\title{
A IMPORTÂNCIA DO FEEDBACK NA EDUCAÇÃO A DISTÂNCIA
}

\author{
LA IMPORTANCIA DEL FEEDBACK EN LA EDUCACIÓN A DISTANCIA
}

THE IMPORTANCE OF THE FEEDBACK IN DISTANCE EDUCATION

\author{
Elaine Marques Cardoso DOSE ${ }^{1}$
}

RESUMO : O presente artigo tem por finalidade apresentar a importância do feedback na educação a distância como auxílio na comunicação e interação entre professores e alunos. Foram apresentadas algumas definições de feedback, assim como detalhes imprescindíveis no processo de ensino-aprendizagem. Realizou-se uma pesquisa bibliográfica considerando as contribuições de vários autores procurando destacar a importância do feedback na comunicação entre professor e aluno. Por fim, de acordo com os estudos foram sugeridos critérios para a elaboração de um feedback adequado com o objetivo de auxiliar a prática docente.

PALAVRAS-CHAVE: Feedback. Comunicação virtual. Interação. Educação a distância.

RESUMEN: El presente artículo tiene por finalidad presentar la importancia de la retroalimentación en la educación a distancia como ayuda en la comunicación e interacción entre profesores y alumnos. Se presentaron algunas definiciones de retroalimentación, así como detalles imprescindibles en el proceso de enseñanzaaprendizaje. Se realizó una investigación bibliográfica considerando las contribuciones de varios autores buscando destacar la importancia del feedback en la comunicación entre profesor y alumno. Por último, de acuerdo con los estudios se sugirieron criterios para la elaboración de un feedback adecuado con el objetivo de auxiliar a la práctica docente.

PALABRAS CLAVE: Feedback. Comunicación virtual. Interacción. Educación a distancia.

ABSTRACT This article aims to present the importance of feedback in distance education as an aid in communication and interaction between teachers and students. Some definitions of feedback have been presented, as well as essential details in the teaching-learning process. A bibliographical research was carried out considering the contributions of several authors seeking to highlight the importance of feedback in the communication between teacher and student. Finally, according to the studies, criteria

${ }^{1}$ Universidade Federal Flumininense (Uff), Volta Redonda - RJ - Brasil. Mestranda em Tecnologia Ambiental. Professora e Programadora de Internet - AETE - Assessoria EAD e Tecnologias Educacionais, no Centro Universitário Barra Mansa (Ubm), Barra Mansa - RJ - Brasil. E-mail: elaine.dose@ubm.br. 
were suggested for the elaboration of adequate feedback with the objective of assisting the teaching practice.

KEYWORDS: Feedback. Virtual communication. Interaction. Distance education.

\section{Introdução}

Com o avanço das tics (Novas Tecnologias de Informação e Comunicação) direcionadas aos avas (Ambientes Virtuais de Aprendizagem) a Educação a Distância (ead) vem tomando força para que professores e alunos, cada vez mais tenham uma comunicação e uma interação efetiva e contam com algumas ferramentas importantes para que essa interação desencadeie o sucesso da construção do conhecimento no processo de ensino aprendizagem. Uma dessas ferramentas é o feedback.

Por isso, se faz necessário entender que a Educação a distância amplia possibilidades de aprendizado através de recursos virtuais com as mais variadas ferramentas, com atividades planejadas e desenvolvidas para atender a um variado público de estudantes, não importando a sua localização geográfica. Nesse âmbito, Moore e Kearsley (2010, p. 2) conceituam da seguinte forma:

A educação a distância é o aprendizado planejado que
ocorre normalmente em um lugar diferente do local do
ensino, exigindo técnicas especiais de criação do curso
e de instrução, comunicação por meio de várias
tecnologias e disposições organizacionais e
administrativas especiais.

Conceitua-se também, a comunicação virtual, no tocante em que a mesma se dá de diversas maneiras e pressupõe a interação onde o feedback é utilizado como ferramenta para retorno do aprendizado. Franco e Braga (2007, p. 1) definem que a “comunicação virtual é toda a comunicação que se faz usando um computador. Podemos comunicar recorrendo ao teclado, ao som e à imagem. A comunicação pode ocorrer em tempo real - síncrona (bate-papo), ou off-line - assíncrona, deixando mensagens (e-mails)." A partir disso utilizando-se da comunicação virtual, a interação surge com a necessidade de expressar algo sobre "o que se quer aprender" e "o que se quer ensinar", assim como, “o que se quis ensinar" e "o que foi aprendido". E um dos 
recursos usadas para se medir a eficácia do processo de ensino-aprendizagem, como resposta é o feedback.

Neste sentido, o presente estudo visa demonstrar a contribuição da ferramenta feedback utilizada durante a interação virtual na construção do conhecimento, na educação a distância.

\section{Desenvolvimento}

A Educação a Distância se faz presente desde o século XIX. Somente, nas últimas décadas começou a receber o crédito em contribuir, significativamente, com o processo de ensino-aprendizagem em vários segmentos da educação, em vários níveis culturais e, principalmente, quebrando o paradigma de que, a educação eficaz é somente, a presencial.

Juntamente, com o advento da tecnologia, a Educação a Distância (ead) toma força e transpõe as barreiras e dificuldades técnicas e culturais, de tempo e distância e, com sua praticidade consegue fazer com que pessoas do mundo todo se instruam e construam o conhecimento através da mediação do computador e da interação com professores e outros alunos.

Não se pode esquecer da contribuição da Internet, a qual seria impossível a comunicação em rede. A capacidade de transmissão de dados em massa com rapidez e interdisciplinaridade de conteúdos e informações, do senso comum, como também, literários e institucionais. Através da Internet temos acesso aos Ambientes Virtuais de Aprendizagem (avas), que permitem integrar vários conteúdos, recursos, informações organizadas, atividades colaborativas e interativas, como o conceito abaixo:

Ambientes digitais de aprendizagem são sistemas computacionais disponíveis na internet, destinados ao suporte de atividades mediadas pelas tecnologias de informação e comunicação. Permitem integrar múltiplas mídias, linguagens e recursos, apresentar informações de maneira organizada, desenvolver interações entre pessoas e objetos de conhecimento, elaborar e socializar produções tendo em vista atingir determinados objetivos. (ALMEIDA, 2003, s/p)

Há uma preocupação muito grande quanto ao desenvolvimento do aluno inserido na Educação a Distância. Um fator que devemos levar em consideração é o 
desenvolvimento da sua autonomia durante a interação e atividades colaborativas, bem como a sua consciência como autor de conhecimentos construídos. Mas é imprescindível que o professor estimule essa interação para que o aluno se sinta seguro ao explicitar suas dúvidas e, ou afirmativas positivas do seu aprendizado, como afirma Dotta $(2009, \mathrm{~s} / \mathrm{p})$ "[...] A postura do educador deve ser dirigida para o trabalho em parceria com o estudante, orientando-o para o diálogo autônomo, o trabalho em projetos e a aprendizagem por pesquisa". A autora acredita que o professor deve ser um moderador da comunicação para a interatividade, tanto na interação professor-aluno como aluno-professor e no ambiente virtual.

Neste contexto, os feedbacks durante o processo de ensino-aprendizagem, nos retornos das atividades propostas como os fóruns conceituais, fórum de dúvidas, emails, blogs e diversas outras ferramentas são relevantes para a construção da autonomia desse aluno e para a sua aprendizagem na educação a distância.

\section{Alguns conceitos de feedbacks, de acordo com alguns autores}

Mory (2004, p. 745-783 apud ABREU-E-LIMA; ALVES, 2011, p. 191) afirma que feedback "é qualquer procedimento ou comunicação realizada para informar o aprendiz sobre a acuidade de sua resposta, geralmente relacionada a uma pergunta instrucional. Ele também pode permitir que o aprendiz compare sua performance atual com a padrão ou a esperada". Também diz que, (idem, p. 192) "Em instrução assistida por computador, feedback é a informação apresentada ao aprendiz logo após qualquer insumo com o propósito de modelar suas percepções". Desta forma, o aluno tem um retorno, na interação, do professor e pode avaliar se a sua linha de estudo está correta, ou que precisa ser reajustada, se redirecionando para a pesquisa e aprendizados esperados, a fim de que, diante de outras avaliações, o seu desempenho seja cada vez melhor.

Paiva (2003, p. 2), define que feedback é a "reação à presença ou ausência de alguma ação com o objetivo de avaliar ou pedir avaliação sobre o desempenho no processo de ensino-aprendizagem e de refletir sobre a interação de forma a estimulá-la, controlá-la ou avaliá-la”. Neste contexto, a autora entende que o feedback pode ser dado por um colega de curso ou mesmo por alguém que não faz parte do ambiente de 
aprendizagem em si, como coordenador ou outro professor, etc. E que consideremos tanto a aprendizagem, como também a interação com fins avaliativos.

Shute (2008, p. 153) define o feedback como formativo: "é a revisão como informação comunicada para o aprendiz com a intenção de modificar seu comportamento ou seu modo de pensar objetivando uma melhoria no aprendizado". Entende-se que, para que o feedback formativo produza mudanças significativas no aluno, que ele seja transmitido no tempo certo, com a quantidade e qualidade de informação corretas e com linguagem adequada. Shute ainda cita que, o feedback formativo pode ser de modo diretivo e sugestivo. O primeiro aponta o que precisa ser corrigido ou modificado; o segundo apresenta comentários e sugestões para orientar o aluno como revisar seu trabalho. O modelo adequado será definido de acordo com o nível do estudante e a complexidade da atividade.

Para se formular um feedback deve-se atentar para a linguagem a ser utilizada e seguir alguns critérios importantes evitando problemas de interpretação:

$\checkmark$ Emoção: deve-se tomar cuidado ao transmitir o que se está sentindo no momento; uma sugestão seria os Emoticons.

$\checkmark$ Tom da mensagem, agradável: curioso, analítico, norteador, crítico; e desagradável: sarcástico, ameaçador, autoritário.

$\checkmark$ Usar a Netiqueta.

$\checkmark$ Correção, coesão e coerência textuais.

$\checkmark$ Clareza e objetividade.

Diante de tantos conceitos importantes sobre feedback ressalta-se que o mesmo deve ser uma ferramenta de avaliação, um recurso de interação para que os envolvidos no processo de ensino-aprendizagem possam se direcionar e se necessário reavaliar a sua performance na Educação a Distância.

\section{Considerações finais}

A partir deste estudo pode-se dizer que a Educação a Distância (ead) contribui eficientemente, para a sucessão do processo de ensino-aprendizagem em todos os âmbitos e segmentos da educação através da Internet e, principalmente, dos Ambientes 
Virtuais de Aprendizagem (avas). Assim, a comunicação virtual faz a ponte na interação entre os diversos atores no ambiente de aprendizagem, professores, alunos, coordenadores e outrem.

Ainda assim, fundamentalmente, a postura do educador deve ser de mediação e parceria com o estudante durante o aprendizado para se obter resultados satisfatórios e, como ferramenta relevante de avaliação o feedback é fundamental como resposta aos estímulos podendo ser formativo, onde o aprendiz recebe o feedback com a intenção de modificar o seu comportamento ou ponto de vista buscando o seu aperfeiçoamento; como feedback formativo pode ser "diretivo"(que aponta o que precisa ser corrigido ou modificado) e "sugestivo"(que apresenta comentários e sugestões como orientação ao revisar o trabalho.

Conclui-se que o feedback deve ser elaborado seguindo critérios importantes para que se atinja o objetivo proposto e que, ele é imprescindível para se ter a certeza de que conteúdos foram assimilados e, se não, a partir deste ponto propor novas interações e estímulos para que a construção do conhecimento aconteça plenamente.

\section{REFERÊNCIAS}

ABREU-E-LIMA, D. M. De.; ALVES, M. N. O feedback e sua importância no processo de tutoria a distância. Proposições, Campinas, v. 22, n.2, ago. 2011.

ALMEIDA, M. E. B. de. Educação a distância na internet: abordagens e contribuições dos ambientes digitais de aprendizagem. Educação e Pesquisa, São Paulo, v.29, n.2, p. 327-340, jul./dez. 2003.

DOTTA, S. Desafios para o diálogo em Educação a Distância. Disponível em: <http://www.moderna.com.br/moderna/didaticos/sup/artigos/2006/082006-01.htm>. Acesso em: 15 Set. 2015.

FRANCO, L. R. H.; BRAGA, D. B. Comunicação virtual. Livro Digital. Curso de Design Instrucional para ead Virtual. Itajubá: UNIFEI, 2007.

MOORE, M.; KEARSLEY, G. Educação a Distância. São Paulo: Thomson Pioneira, 2007.

PAIVA, V. L. M. O. Feedback em Ambiente Virtual. In: LEFFA, V. (Org.) Interação na aprendizagem das línguas. Pelotas: EDUCAT, 2003.

SHUTE, V. J. Focus on formative feedback. Review of Educational Research, Princeton, v.1, n. 78, p. 153-189, 2008. 


\section{Como referenciar este artigo}

DOSE, Elaine Marques Cardoso A importância do feedback na educação a distância. Revista on line de Política e Gestão Educacional, Araraquara, v.21, n.3, p. 15651571, set./dez. 2017. ISSN: 1519-9029.

Submetido em: 28/10/2017

Aprovado em: 20/12/2017 